\title{
Surface functionalization of HF-treated silicon nanowires
}

\author{
MING-WANG SHAO ${ }^{1, *}$, HONG WANG $^{1}$, YAN FU $^{1}$, JUN HUA $^{1}$ and \\ DOROTHY-DUO-DUO MA ${ }^{2}$ \\ ${ }^{1}$ Anhui Key Laboratory of Functional Molecular Solids, and College of Chemistry and Materials Science, \\ Anhui Normal University, Wuhu 241000, P.R. China \\ ${ }^{2}$ Center of Super-Diamond and Advanced Films (COSDAF) and \\ Department of Physics and Materials Science, City University of Hong Kong, Hong Kong SAR (China) \\ e-mail: mwshao@mail.ahnu.edu.cn
}

MS received 18 December 2007; revised 11 March 2009

\begin{abstract}
Versatile methods were employed to investigate the chemical reactivity of hydrogenterminated surface of silicon nanowires. The experimental results showed that coupling reaction took place when silicon nanowires reacted with 2,2,2-trifluoroethyl acrylate, and reductive deposition reaction occurred in the presence of inorganic salt such as $\mathrm{HgCl}_{2}$, and also co-reduction reaction took place in a solution containing both $\mathrm{AuCl}_{3}$ and $\mathrm{PdCl}_{2}$. The possible reaction mechanisms were studied and this study would be expected to favour the homogeneity, selectivity, reproducibility, and stability of SiNW devices or sensors.
\end{abstract}

Keywords. Silicon nanowires; reactivity; mercurous chloride; 2,2,2-trifluoroethyl acrylate; Au-Pd bimetal.

\section{Introduction}

One-dimensional (1D) nanostructures, such as nanorods, nanowires, nanotubes and nanobelts have been attracting a lot of interests for their unique potential applications. ${ }^{1-6}$ Nanowires are bright members in the various nanostructures because they possess excellent properties such as high aspect ratios, fine flexibility, ease of combination, high sensitivity and selectivity which are perfect for nano-devices and nanosensers. Silicon nanowires (SiNWs) have attracted great attention, because silicon is of great technological importance in microelectronics. ${ }^{7}$ Moreover, SiNWs provide a number of advantages: unique semiconducting, mechanical, optical and field-emission properties, ${ }^{8,9}$ and a vast surface-tovolume ratio. ${ }^{10}$ These properties make them particularly appealing in the application of a variety of fields, such as constructing nanoscale electric, optoelectric devices ${ }^{1-13}$ and biological applications: detection of $\mathrm{fM}$ level of protein ${ }^{14}$ and DNA. ${ }^{15}$

Hence, many successful synthesis strategies to obtain bulk quantities of SiNWs have been developed using laser ablation or thermal evaporation of silicon

\footnotetext{
*For correspondence
}

powder, ${ }^{16-19}$ and solvothermal method, ${ }^{20,21}$ which provide sufficient quantities of SiNWs for the detailed studies of their physical and chemical properties as well as applications.

One of the special interests of SiNWs is that their surfaces can be easily modified to act as both electron-transfer mediator and immobilizing matrices for biological or chemical molecules. ${ }^{22}$ The chemical properties of SiNWs surfaces are crucial to their application in mesoscopic electronic devices in terms of stability and transport properties. Currently, many studies have been involved in the modification and reactivity of SiNWs. Park et al have selectively functionalized the SiNWs via nanoscale Joule heating. ${ }^{23}$ Shir et al investigated the oxidation of silicon nanowires. ${ }^{24}$ Leu et al have systematically investigated different surface coverage $(\mathrm{H}, \mathrm{Br}, \mathrm{Cl}$, and I) using $a b$ initio density functional theory calculations. ${ }^{25}$

In this paper, the organic molecule such as 2,2,2trifluoroethyl acrylate, and inorganic mercurous chloride and the mixture solution of $\mathrm{AuCl}_{3}$ and $\mathrm{PdCl}_{2}$ were taken for the example to study the reactivity of SiNWs, which is an activity agent when refreshed with HF solution. This study on reactivity of SiNWs would be expected to favour the homogeneity, se- 
lecivity, reproducibility, and stability of SiNW devices or sensors.

\section{Experimental}

SiNWs, prepared as previous report, ${ }^{26}$ were etched with $5 \% \mathrm{HF}$ aqueous solution for $5 \mathrm{~min}$, then picked out and sopped up the remanent solution for the following experiments.

\subsection{Reaction of SiNWs with 2,2,2-trifluoroethyl acrylate}

The as-treated SiNWs were added into and reacted with 2,2,2-trifluoroethyl acrylate $\left(\mathrm{CH}_{2}=\mathrm{CHCOO}\right.$ $\mathrm{CH}_{2} \mathrm{CF}_{3}$ ) under the irradiation of $270-340 \mathrm{~nm} \mathrm{UV}$ lamp for $12 \mathrm{~h}$. After sopped up, the as-treated products were put in chloroform under ultrasonic treatment for $10 \mathrm{~min}$ to remove unreacted trifluoroethyl acrylate, and then hydrolysed in methanol aqueous solution for another 10 min ultrasonic treatment.

\subsection{Reduction deposition of $\mathrm{Hg}_{2} \mathrm{Cl}_{2}$}

The as-treated SiNWs were added into and reacted with $\mathrm{HgCl}_{2}$ solution until the yellow SiNWs turned dark grey.

\subsection{Co-reduction reaction of $A u-P d$ bimetal}

The as-treated SiNWs were immersed in $4 \mathrm{ml}$ mixture solution, which were composed of $2 \mathrm{ml} 5 \times 10^{-3} \mathrm{M}$ $\mathrm{AuCl}_{3}$ aqueous solution and $2 \mathrm{ml} 5 \times 10^{-3} \mathrm{M} \mathrm{PdCl}_{2}$ aqueous solution. When the yellow SiNWs gradually turned black, it indicated that they were modified with $\mathrm{Au}-\mathrm{Pd}$ bimetal.

\subsection{Characterization}

The phase purity of the as-prepared products was determined by a Shimadzu XRD-6000 X-ray diffractometer equipped with $\mathrm{CuK} \alpha$ radiation $(\lambda=$ $0.15406 \mathrm{~nm})$. A scanning rate of $0.05 \mathrm{~s}^{-1}$ was applied to record the pattern. The morphology and nanostructure of the nanocomposites were carried out with a field emission scanning electron microscope (FESEM) (S 4800), transmission electron microscope (TEM) (Hitachi H-800), and a high-resolution transmission electron microscope (HRTEM) (JEOL2010). X-ray photoelectron spectroscopy (XPS) was recorded on a VGESCALAB MK II X-ray photoelectron spectrometer, using non-monochromatized $\mathrm{Al} \mathrm{K} \alpha \mathrm{X}$-ray as the excitation source. The binding energy of contaminated carbon $(\mathrm{C}$ 1s: $284.6 \mathrm{eV})$ was used as the reference.

\section{Results and discussion}

Figure la shows the XRD pattern of as-prepared SiNWs, and all diffraction peaks can be indexed as the cubic phase of Si (JCPDS 27-1402). The SEM image (figure 2a) reveals that the sample takes the shape of a wire, which is smooth and with the average diameter of $25 \mathrm{~nm}$. Figure $2 \mathrm{~b}$ presents a TEM image of SiNWs, which indicates high degree of crystallinity from the bright stripes. HRTEM image (figure 2c) shows clear lattice fringes with distance of $0.318 \mathrm{~nm}$, which correspond to the (111) and (-111) planes. The growth direction of the SiNWs is determined as [112].

Figure 3a displays the core level XP spectrum of $\mathrm{Si} 2 \mathrm{p}$ which gives the binding energy $103.2 \mathrm{eV}$. This value is corresponding to that of silicon oxide while the peak at $99.3 \mathrm{eV}$, which belongs to element $\mathrm{Si}$, is hardly observed. It is because core silicon nanowire is covered with a thick silicon oxide layer. When the SiNWs are etched with HF, the element silicon peak at $99.3 \mathrm{eV}$ emerges (figure $3 \mathrm{~b}$ ), and silicon oxide peak at $103.2 \mathrm{eV}$ disappears. These results indicate a silicon oxide layer covered on the SiNWs has been cleared by the HF.

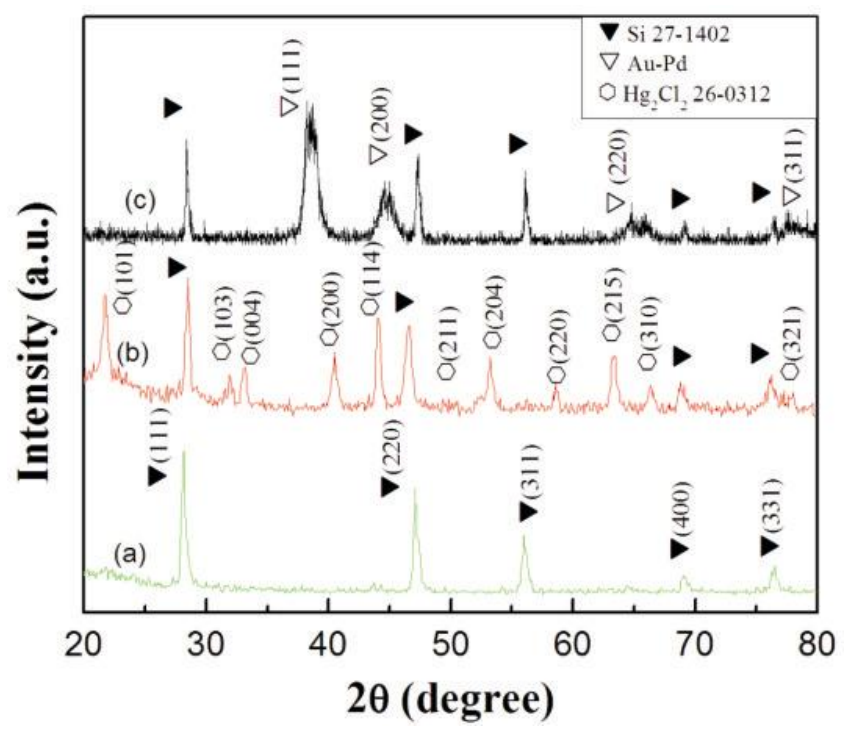

Figure 1. XRD pattern of products: (a) as-prepared $\mathrm{Si}$ nanowires. (b) SiNWs supported $\mathrm{Hg}_{2} \mathrm{Cl}_{2}$. (c) SiNWs supported $\mathrm{Au}-\mathrm{Pd}$ bimetal. 
3.1 Reaction between SiNWs and $\mathrm{CH}_{2}=\mathrm{CHCOOCH}_{2} \mathrm{CF}_{3}$

Organo-modification is in favour of the biological detection expert for the stabilization of ultrafine parti-

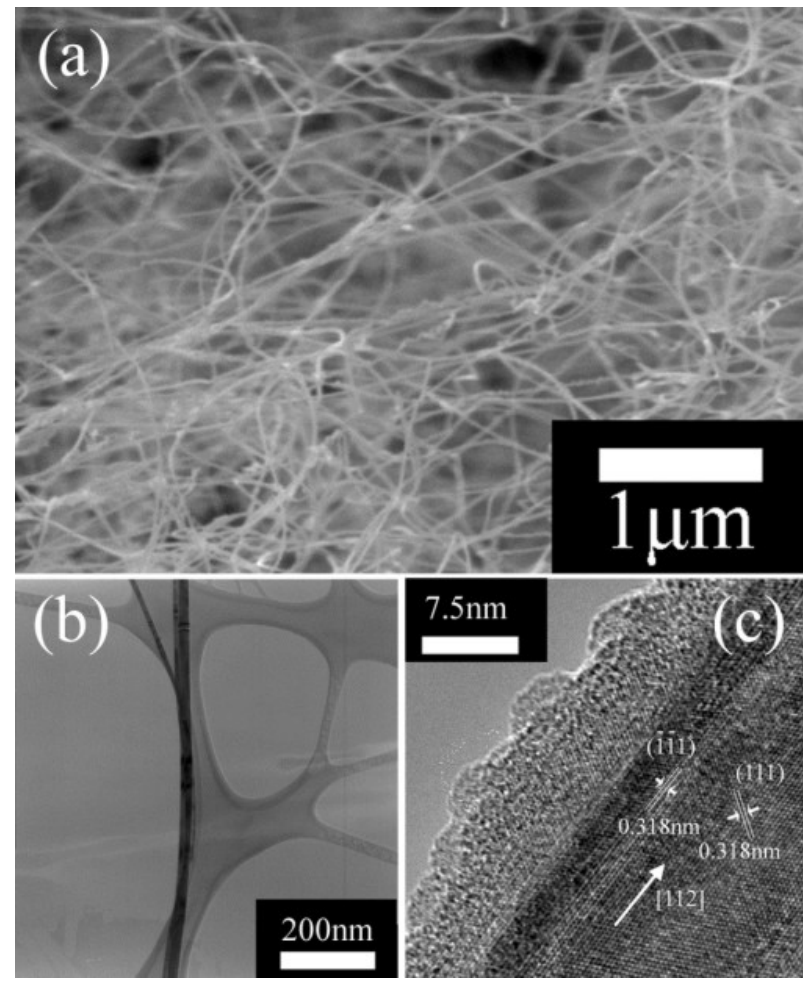

Figure 2. (a) SEM image of as-prepared SiNWs with the average diameter of $25 \mathrm{~nm}$. (b) TEM image of asprepared SiNWs. (c) HRTEM image showing (111) and $(-1-11)$ planes of SiNWs, and the growth direction is determined as [112].

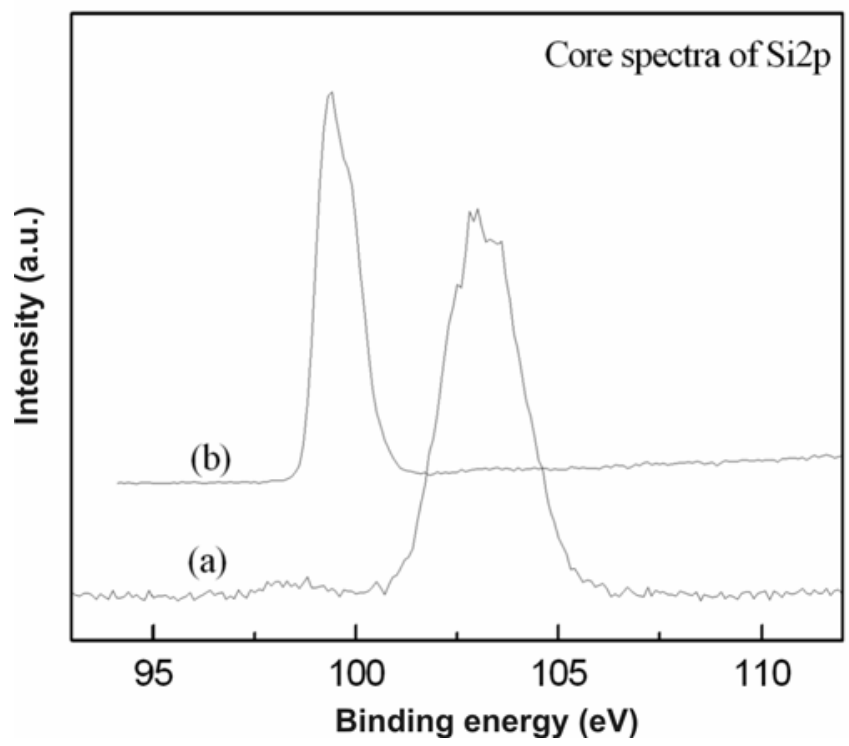

Figure 3. Core spectra of $\mathrm{Si} 2 \mathrm{p}$ of SiNWs: (a) before treated with $\mathrm{HF}$, and (b) after treated with HF. cles. The surface coupling reaction and ester hydrolysis of SiNWs are studied with XPS analysis. 2,2,2trifluoroethyl acrylate is designed to react with the surface of HF-treated SiNWs, the $\mathrm{C}_{1 \mathrm{~s}}$ signal from the trifluoroethyl group is strong and well resolved from other XPS signals, which provides an obvious proof for hydrolysis reaction. The $\mathrm{C}_{1 s}$ signal is strong after the surface reaction and is completely removed by the hydrolysis procedure, proving that the trifluoroethyl group is linked on the surface of SiNWs and then removed away during the modification.

The carbon core spectra (figure $4 \mathrm{a}$ ) shows peaks at 287.5 and $293.0 \mathrm{eV}$ assigned to the carbons in trifluoroethyl group. ${ }^{27}$ And the peaks of the carbonyl carbon and the bulk carbons have been assigned to at 289.3 and $284.4 \mathrm{eV}$, respectively. After hydrolysis, the carbon peaks at 287.5 and $293.0 \mathrm{eV}$ disappear (figure $4 \mathrm{~b}$ ), which confirmed the complete hydrolysis of the ester. In contrast, the XPS signals corresponding to the alkyl chain and carboxylic acid group still exist, demonstrating that the linkage between the alkyl chain and the surface was not disrupted by the hydrolysis reaction. The reaction of the modifying process is as given below:

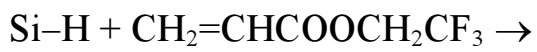

$\mathrm{SiCH}_{2} \mathrm{CHCOOCH}_{2} \mathrm{CF}_{3}$

$$
\begin{aligned}
& \mathrm{SiCH}_{2} \mathrm{CHCOOCH}_{2} \mathrm{CF}_{3}+\mathrm{H}_{2} \mathrm{O} \rightarrow \\
& \mathrm{Si}-\mathrm{CH}_{2} \mathrm{CHCOOH}+\mathrm{CF}_{3} \mathrm{CH}_{2} \mathrm{OH} .
\end{aligned}
$$

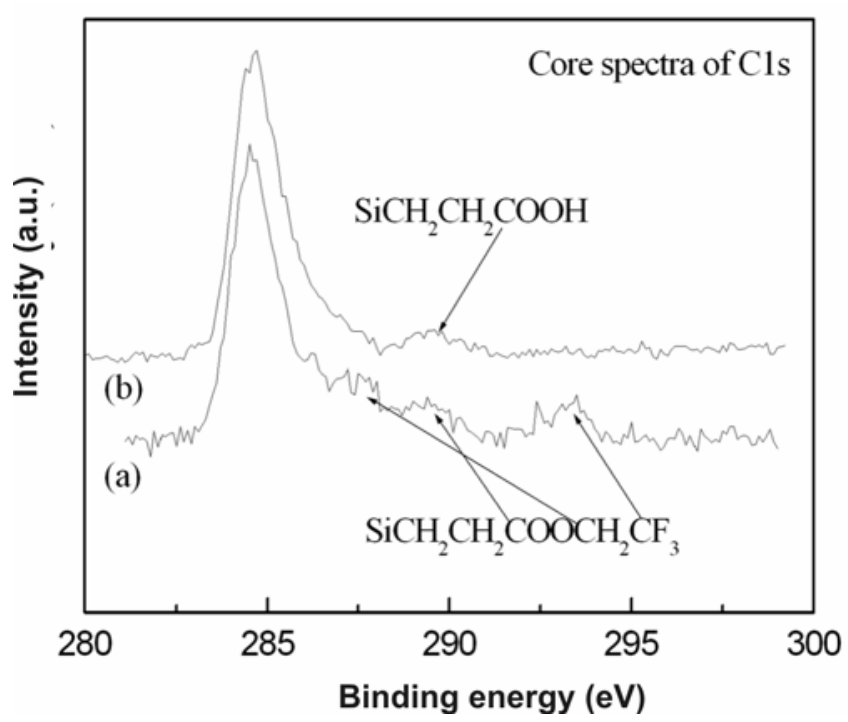

Figure 4. XPS core spectra of C1s of SiNWs: (a) reacted with trifluoroethyl acrylate; and (b) hydrolysed in alcohol aqueous solution. 


\subsection{Reaction between $\mathrm{SiNW}$ and $\mathrm{HgCl}_{2}$}

Figure $1 \mathrm{~b}$ shows the XRD pattern of the resultant, coming from the reaction between treated SiNWs and $\mathrm{HgCl}_{2}$. The diffraction peaks can be indexed to $\mathrm{Hg}_{2} \mathrm{Cl}_{2}$ (JCPDS 26-0312) besides silicon (JCPDS 27-1402), indicating that the reaction between treated SiNWs and $\mathrm{HgCl}_{2}$ is a reduction reaction. Figure 5 displays a TEM image of one single wire modified with $\mathrm{Hg}_{2} \mathrm{Cl}_{2}$, which elucidates that the reduction reaction took place on the surface of SiNWs.

The probable reaction mechanism might be written as follows: first, the oxides on the surface of SiNWs are removed with HF. Then, the hydrogen atom-silicon interaction leads to the formation of surface hydrides (from monohydride to trihydride). ${ }^{28}$ Last, upon the reaction with $\mathrm{HgCl}_{2}, \mathrm{Si}-\mathrm{H}$ bond is intimately in the reaction yielding $\mathrm{H}_{2}$ and $\mathrm{Hg}_{2} \mathrm{Cl}_{2}$. It reveals that SiNWs is a modest reducing agent when refreshed with HF solution. The reduction reaction can be briefly described as:

$$
\begin{aligned}
4 \mathrm{Si}-\mathrm{H}(\text { surface })+2 & \mathrm{HgCl}_{2} \rightarrow \mathrm{Hg}_{2} \mathrm{Cl}_{2}+\mathrm{H}_{2} \\
+ & 2 \mathrm{HCl}+4 \mathrm{Si} \text { (surface). }
\end{aligned}
$$

This reactivity of SiNWs might be applied in the detection and the wastewater treatment.

\subsection{Reaction between $\mathrm{SiNWs}$ and $\mathrm{PdCl}_{2}$ and $\mathrm{AuCl}_{3}$}

Because of the excellent catalysis of $\mathrm{Au}-\mathrm{Pd}$ bimetal, the coreduction reaction was carried out using the mixture of $\mathrm{PdCl}_{2}$ and $\mathrm{AuCl}_{3}$. Figure 1c shows the X-ray diffraction (XRD) pattern of the SiNWsupported $\mathrm{Au}-\mathrm{Pd}$ nanoparticles. No other characteristic peaks were observed except for Si (JCPDS $27-$ 1402) and $\mathrm{Au}-\mathrm{Pd}$ bimetal, which indicates that the

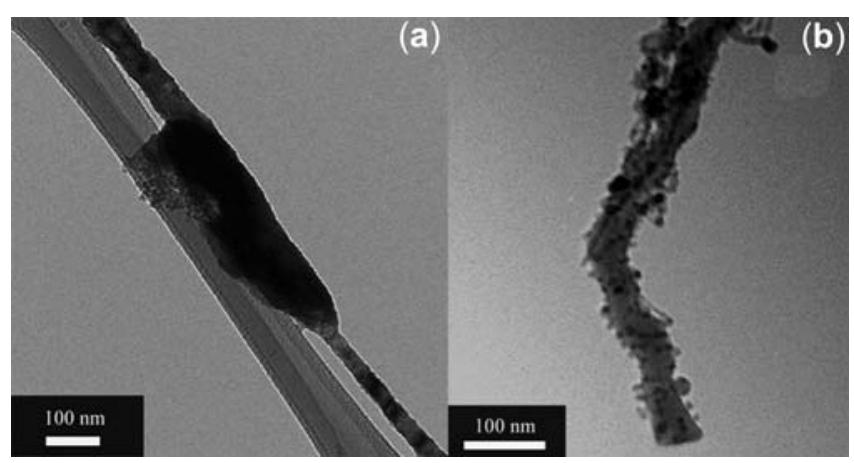

Figure 5. TEM image of one single wire (a) modified with $\mathrm{Hg}_{2} \mathrm{Cl}_{2}$, (b) supported with $\mathrm{Au}-\mathrm{Pd}$ bimetal. product has high purity. A peak between the characteristic peak of $\mathrm{Au}(2 \theta=38 \cdot 2)(\mathrm{JCPDS}$ 04-0784) and that of $\operatorname{Pd}(2 \theta=40 \cdot 1)$ (JCPDS 46-1043), further pointing that $\mathrm{Au}-\mathrm{Pd}$ bimetallic system was present with the $\mathrm{Au}: \mathrm{Pd}$ atomic ratio of $2: 1$ calculated according to Vegard's law. ${ }^{29}$

Figure $5 \mathrm{~b}$ presents a TEM image of one single wire supported with $\mathrm{Au}-\mathrm{Pd}$ bimetal, which are randomly attached to the surface of SiNW, taking an average diameter of $8 \mathrm{~nm}$.

The above characterization results are consistent with each other and prove that the $\mathrm{Au}-\mathrm{Pd}$ bimetal have been co-reduced simultaneity due to the activity of the surface of treated SiNWs.

Based on the above reaction mechanism, it could be deduced that the interaction of SiNWs with $\mathrm{Pd}^{2+}$ and $\mathrm{Au}^{3+}$ ions is a coreduction process, which involves the electrons transfer to the metal ions absorbed on the surface of SiNWs from the Si atom on the surface, meanwhile the $\mathrm{Si}-\mathrm{H}$ evolves to hydrogen gas simultaneously. The coreduction process is illustrated in the equation:

$$
\begin{array}{r}
4 \mathrm{Si}-\mathrm{H}(\text { surface })+\mathrm{PdCl}_{2} \rightarrow \mathrm{Pd}+\mathrm{H}_{2} \\
+2 \mathrm{HCl}+4 \mathrm{Si} \text { (surface). } \\
5 \mathrm{Si}-\mathrm{H}(\text { surface })+\mathrm{AuCl}_{3} \rightarrow \mathrm{Au}+\mathrm{H}_{2}+ \\
3 \mathrm{HCl}+5 \mathrm{Si} \text { (surface). }
\end{array}
$$

$$
\mathrm{Au}+\mathrm{Pd} \rightarrow \mathrm{Au}-\mathrm{Pd} \text { (bimetal). }
$$

\section{Conclusions}

The reactivity of SiNWs was systematically investigated by the reaction with organic and inorganic compounds, which showed HF-treated SiNWs is an activity agent, and an attractive host for other supported compounds. The study on the reaction mechanism is propitious to functionalize the SiNWs. It provides an avenue for the development of devices in which the exquisite binding specificity of biomolecular recognition is directly coupled with semiconductor devices.

\section{Acknowledgements}

The financial support from the National Natural Science Foundation of China (20571001), the Education Department (No. 2006KJ006TD) of Anhui Province and Anhui Provincial Natural Science Foundation (070414185) are acknowledged. 


\section{References}

1. Alivisatos A P 1996 Science 271933

2. Frank S, Poncharal P, Wang Z L and Heer W A 1998 Science 2801744

3. Yakobson B L and Smalley R E 1997 Am. Sci. 85324

4. Duan X F and Liber C M 2000 J. Am. Chem. Soc. 122 188

5. Wang Z L $2000 A d v$. Mater. 121295

6. $\mathrm{Hu}$ J, Odom T W and Lieber C M 1999 Acc. Chem. Res. 32435

7. Sun $X \mathrm{H}$, Samnyaiken $\mathrm{R}$, Naftel $\mathrm{S} J$, Tang $\mathrm{Y} \mathrm{H}$, Zhang P, Kim P S, Sham T K, Fan X H, Zhang Y F, Lee C S, Lee S T and Wong N B 2002 Chem. Mater. 142519

8. Zhang Y F, Tang Y H, Wang N, Yu D P, Lee C S, Bello I and Lee S T 1998 Appl. Phys. Lett. 721835

9. Morales A M and Lieber C M 1998 Science 279208

10. Yu D P, Bai Z G, Ding Y, Hang Q L, Zhang H Z, Wang J J, Zou Y H, Qian W, Xiong G C, Zhou H T and Feng S Q 1998 Appl. Phys. Lett. 2833458

11. Wang N, Tang Y H, Zhang Y F, Lee C S, Bello I and Lee S T 1999 Chem. Phys. Lett. 299237

12. Alivisatos A P 1996 Science 271933

13. Pei L Z, Tang Y H, Chen Y W, Guo C, Zhang W and Zhang Y 2006 J. Crystal Growth 289423

14. Zheng G, Patolsky F, Cui Y, Wang W U and Lieber C M 2005 Nat. Biotechnol. 231294

15. Hahm J and Lieber C M 2004 Nano Lett. 451
16. Nikolaides M G, Rauschenbach $\mathrm{S}$ and Bausch A R 2004 J. Appl. Phys. 953811

17. Wong W K, Meng F Y, Li Q, Au F C K, Bello I and Lee S T 2002 Appl. Phys. Lett. 80877

18. Cui Y, Wei Q Q, Park H K and Lieber C M 2001 Science 2931289

19. Xia Y N, Yang P D, Sun Y G, Wu Y Y, Mayers B, Gates B, Yin D, Kim F and Yan H Q $2003 A d v$. Mater. 15353

20. Nath M and Parkinson B A 2006 Adv. Mater. 181865

21. Chen C L, Chen D R, Jiao X L and Wang C Q 2006 Chem. Commun. 4632

22. Shao M W, Shan Y Y, Wong N B and Lee S T 2005 Adv. Funct. Mater. 151478

23. Park I, Li Z Y, Pisano A P and Willianms R S 2007 Nano Lett. 103106

24. Shir D, Liu B Z, Mohammad A M, Lew K K and Mohney S E 2006 J. Vac. Sci. Technol. B24 1333

25. Leu Paul W, Shan B and Cho K 2006 Phys. Rev. B73 195320

26. Lee S T, Wang N, Zhang Y F, Zhang Y H, Tang Y H, Bello I, Lee C S and Chung Y W 1999 J. Mater. Res. 144503

27. Strother T, Cai W, Zhao X S, Hamers R J and Smith L M 2000 J. Am. Chem. Soc. 1221205

28. Lu Z H, Griffiths K, Norton P R and Sham T K 1992 Phys. Rev. Lett. 681343

29. Denton A R and Ashcroft N W 1991 Phys. Rev. A6 3161 